\title{
Homelessness and access to the informational mainstream
}

Thomas H. Muggleton

E-mail:tmuggleton@hotmail.co.uk

University of Strathclyde, Glasgow, UK

Ian Ruthven

University of Strathclyde, Glasgow, UK

\section{Abstract \\ Purpose}

To explore how homelessness affects access to information serving higher-level needs such as identity formation and social interaction.

\section{Design/methodology/approach}

A multi-disciplinary literature review informed the design of 18 semi-structured interviews as well as their subsequent analysis. The interview data was intended to be qualitative and exploratory since it addressed a perceived gap in the information and library science literature.

\section{Findings}

Findings present the ways in which interviewees managed to access information and the way such information helps socialisation and well-being.

\section{Research limitations/implications}

The study focused on individuals who were potentially more confident and resourceful. The study is also limited to Glasgow which has relatively good provision for the homeless. Further research in a different locale and among less confident individuals would be necessary to corroborate findings in this regard.

\section{Practical implications}

The findings confirmed a fundamental research assumption that homeless individuals would pursue higher-level needs alongside more basic physiological needs. This has practical implications for public libraries' service provision to homeless populations, and also suggests there is greater room for collaboration between libraries and homeless service agencies.

\section{Originality/value}


The paper addresses a gap in the literature concerning homelessness and higher-level needs. This has implications for the provision of information and services within both public libraries and organisations serving the homeless. Findings also challenge widespread assumptions regarding the 'otherness' or distinctiveness of people who are homeless.

\section{Research paper}

Keywords: homelessness, social interaction, identity formation, information provision

Received: $11^{\text {th }}$ February 2011

Revised: $21^{\text {st }}$ June 2011

Accepted: $13^{\text {th }}$ June 2011 


\section{Introduction}

The centrality of information to human experience is undeniable; from individual concerns over identity and social interaction, to societal shifts and political decisionmaking, it is information that forms, influences and redefines many of the thoughts and actions that are considered uniquely human. The importance of information to human society and individuals has, throughout history, driven technological developments that have impacted on people's ability to record, store and transmit information. However, although technology has greatly increased the capacity to store, process and transmit information, there are still significant economic, educational and social barriers facing many people in terms of information access.

As well as throwing up new barriers for some people, technological developments have also impacted upon the mass media as the popularity of old technologies has waned and new information seeking behaviours have emerged. However, although it is in a state of flux, the current information environment is still fairly centralised and, in terms of both content and major providers, limited in coverage, size and scope. This creates what has been described in this paper as an 'informational mainstream' that is accessed by a significant proportion of the population and in many situations lends content to social interaction. The existence of an informational mainstream coupled with potential barriers in accessing it raises the question of social exclusion; namely, how a lack of access to the informational mainstream may feed into the "multi-dimensional cumulative disadvantage" (Daly and Silver, 2008, p. 549) discussed in the academic literature on social exclusion.

In response to this question, our research aimed to address the effects that homelessness has on access to information sources that are pertinent to identity formation and social interaction, such as newspapers, television, radio, books and the internet. That is, we sought to investigate whether being homeless presents obstacles to accessing information pertinent to identity formation and social interaction, and secondly, whether this would compound existing difficulties of social exclusion for an already marginalised group. This was considered significant as it would negatively affect people's ability to meet higher-level needs such as belonging, self-esteem and self-actualisation. 
Overall, the research aimed to address a perceived gap in the library and information science literature concerning higher-level needs among people who are homeless. There is an understandable tendency within the library and information science literature that addresses homelessness to focus on information required to meet basic physiological needs. Although this focus on practical information is understandable when considering such a physically vulnerable group of people, it was felt that this may cause important higher-level needs, and the information that serves these needs, to be neglected.

In the following section (section 2), we outline what we see as the current information environment and present definitions of homelessness and the homeless experience. This section provides an overview of these conditions to provide the context for our study. Section 2 closes with a description of literature about the potential impact of homelessness on access to information services and the research questions we hope to address. In section 3 we outline our study, including a discussion on the nature of the methodology and analysis. In section 4 we present our findings grouped under four main research questions. We conclude with a discussion and possible implications of our research.

\section{Related work}

\subsection{The current information environment}

The technological developments of the last 200 years have exponentially magnified human beings' ability to both record and transmit information. In particular, the rise of formats during the $20^{\text {th }}$ century that have collectively come to be known as the 'mass media' “...gave more access to more information to more people than at any time in history." (Feather, 2008, p. 27). Both television and radio have served to reassert the position of oral and visual culture in the UK and elsewhere (Feather, 2008, p. xvi, 27). As well as providing information that is arguably easier to absorb than the printed word (Feather, 2008, p. 25), radio and particularly television have given people more direct access to events and current affairs, and have subsequently changed the way people perceive the world (Feather, 2008, pp. 26-27). The 
popularity of these media reflects this; today, of the 26.8 million households in the UK, 26 million own a television (BARB, 2010), while 91\% of the UK population tune into a radio station at some point during a normal week (RAJAR, 2010).

More recent developments in computing and telecommunications have further increased the capacity to record and transmit information (Feather, 2008, pp. 28, 3236). The uptake of these new technologies has also mirrored that of television and radio. The latest figures from the Office of National Statistics show that, in 2006, $60 \%$ of people in the UK had been on the internet in the last three months, which rises to $84 \%$ of people between the ages of 16 and 24 (Office for National Statistics, 2010).

Despite the emergence of new technology, books and newspapers are still popular sources of information and support significant and lucrative industries. Total UK book sales at retail value in 2008 were $£ 3,436$ m (BML, 2010), while the ten most popular national daily and national Sunday newspapers in the UK had a combined circulation of 11,552,314 and 12,162,801 respectively in 2006 (Willings Press Guide., 2007). These industries have also benefited from new technology in numerous ways, particularly in terms of production. Indeed, although the book industry has experienced declining revenues in recent years, publishing has expanded significantly compared to 25 years ago; the number of book titles published had risen to 119,001 by 2001 compared to 48,085 in 1986, an increase of $147 \%$ (BML, 2010).

Given the extent of their usage it seems reasonable to consider television, radio, the internet, books and newspapers as mainstream sources of information.

\subsection{The homeless}

In a capitalist society, a premium is placed on ownership of property and there is a multifaceted burden placed on those who find themselves homeless in such societies. However, although the term 'homeless' may seem straightforward and selfexplanatory, it is problematic for a number of reasons. 
Firstly, Hersberger has highlighted the heterogeneous nature of people termed 'homeless' (Hersberger, 2005, p. 199); there are numerous reasons why people become homeless, no inevitable patterns of behaviour exist among homeless people, and, subsequently, no single way of leaving homelessness. There is also wide demographic variation among those termed homeless, in terms of age, ethnic origin, length of homelessness, etc., making the term 'homelessness' limited in what it describes. This is a particularly important caveat due to the often negative associations with the term. Hersberger has warned against the stigmatising effects of considering someone primarily as a homeless person and potentially, by association, an "unworthy" recipient of public services (Hersberger, 2005, p. 199).

Secondly, there is the issue of what being 'homeless' actually means. A number of studies in the library and information science literature (Hersberger, 2005, p. 199; Le Dantec and Edwards, 2008, pp. 627-628; Woelfer and Hendry, 2009, p. 2301) cite the Stewart B. McKinney Act, 42 U.S.C. §11301, et seq., which includes people “... who [lack] a fixed, regular, and adequate night-time residence" and people in temporary accommodation, as well as those who are sleeping rough and are perhaps more visibly 'homeless' (Office of the Law Revision Counsel, 2009, Sec. 11302). In similarly acknowledging people in temporary accommodation as homeless, Cronley et al. include those staying in hotels and motels and those who are temporarily staying with friends or family as constituting part of the homeless population (Cronley et al., 2009, p. 483). As will be explained in section 3, our participants were adult males who attended a local charity for vulnerable and disadvantaged citizens. In effect, these were adults who self-identified as being homeless at some point in their lives, although some had now secured more permanent accommodation and would no longer consider themselves as such.

\subsection{The social world of the homeless}

Conley argued that previous studies involving homeless people could be divided into those which portray the social world of homeless people as a cohesive subculture, and those which cast homeless people as social deviants, isolated from wider society and each other (Conley, 1996, p. 27). In reality, and as we discuss below, some 
combination of socialisation and isolation is true for many (Conley, 1996, p. 28). Either way, it seems likely that the social norms of one's homeless peers will in many cases influence behaviour (Conley, 1996, p. 27).

Most homeless people cannot afford to isolate themselves from their peers, who they rely on for emotional and material support. Therefore, to survive day-to-day, an individual may be forced to adhere to certain behavioural norms (Conley, 1996, p. 27). Indeed, disadvantaged groups tend to be more reliant on informal networks in terms of social capital, as their status hinders participation in more formal civic engagement (Daly and Silver, 2008, pp. 548-549). Exclusion from formal social networks and institutions may be particularly problematic for homeless people who are often visually stigmatised (Conley, 1996, pp. 32-33, 37). Social exclusion ${ }^{1}$ is also exacerbated for homeless men who frequently receive less sympathy than homeless families, women and children (Sumerlin and Bundrick, 1997, p. 1309). As well as increasing mutual reliance in terms of material support, such exclusion may also contribute to the family-like ties among homeless people identified by Sumerlin (Sumerlin, 1996, p. 888), with the shared experience of homelessness and exclusion contributing to a 'homeless identity’ (Sumerlin, 1996, p. 888).

However, while wider social exclusion and socialisation among the homeless can be mutually reinforcing, this is not necessarily so. Homeless people often regard each other with the same prejudices as others (Conley, 1996, pp. 32-33, 36-37), again underlining the need to avoid simplistic assumptions about 'homeless people' and their differentiation from the rest of society. Although daily survival needs were often addressed collectively, Conley found that many homeless people would make assumptions about their friends that inhibited higher-level cooperation; when the stakes were raised - to rent a house with a friend, for example - the amount of mutual trust required was prohibitive (Conley, 1996, pp. 32-34, 37-38). Indeed, Sumerlin found that, due to previous experiences, distrust was a common attitude towards relationships among the participants in his study (Sumerlin, 1996, p. 887, 889). Regardless of how one explains such assumptions though, homelessness can often be

\footnotetext{
${ }^{1}$ We will work with the operating definition of social exclusion supplied by The Penguin English Dictionary: “.... a situation in which a person or social group lacks the opportunity to participate fully in the social, political, and cultural life of their community" (Penguin English Dictionary, 2007).
} 
a self-reinforcing situation. Through a combination of normative behavioural demands, exclusion from mainstream society, and difficulties with higher-level cooperation among one's peers, it can become increasingly difficult to escape homelessness once one is in that situation.

\subsection{Difficulties facing homeless people}

Although, as alluded to previously, broad generalisations about homelessness are problematic, the homeless do face particular circumstances and difficulties. It is important to consider these and their ensuing physiological and higher-level needs to further contextualise this study. Physiological needs are understandably often considered salient when discussing homelessness. Indeed, meeting basic needs has been found to be the primary concern of most homeless young people (Woelfer et al., 2008, p. 6).

The generally poor economic position of most homeless people means that they face additional difficulties in meeting their basic needs for food, clothing and shelter (Anderson, 1996, p. 369). For those who are newly homeless, and may lack access to informal support networks initially, it is vital to get information about relevant services and how to survive in this environment quickly (Woelfer et al., 2008, pp. 2, 5-6). Furthermore, LaGory et al. found that life choices had a significant impact on quality of life among homeless individuals (LaGory et al., 2001), suggesting that access to the right information could also have a long-term effect. This may be particularly true for homeless young people who face additional difficulties in dealing with the transition to adulthood in the absence of resources and traditional support structures (Barry et al., 2002, p. 146; Woelfer et al., 2008, p. 1).

Overall, the multifarious risks and difficulties that homeless people face in ensuring their daily survival has led Sumerlin to argue that surviving each day can be seen as "an episode of peak performance" (Sumerlin, 1996, p. 885). He feels that acknowledging this is an important part of restoring confidence and self-worth among homeless people (Sumerlin, 1996). Indeed, an excessive focus on addressing material, physiological needs may overlook equally important self-esteem issues for 
homeless people. Perhaps more significantly, this may also inadvertently lead to a damaging perception of the homeless as differentiated 'others', with fundamentally different needs, emotions and desires from anyone else. Instead, it is imperative to remember that homeless people also have higher-level needs such as self-esteem issues and identity concerns.

While this may appear to be a truism, it challenges a widespread belief based on Maslow's pyramid of needs that higher-level needs will not emerge until more basic physiological needs have been met (Snow and Anderson, 1987, p. 1365). Following Snow and Anderson, this paper proceeds from the view that higher-level needs constitute a fundamental part of being human and that these coexist with more physiological needs at all levels of the social spectrum (Snow and Anderson, 1987, p. 1365). If one accepts that higher-level needs coexist with more basic needs, it follows that, as with the latter, homeless people are in a particularly precarious position. Selfesteem issues can be especially difficult for the homeless, and particularly homeless young people, as they have become disconnected from their previous lifestyle and have often lost trust in people important to them, as well as with wider society (Slesnick et al., 2008, p. 728). This can have a disproportionate effect on homeless young people because they become increasingly detached from traditional support systems such as school, family and community during an important period in their personal development (Woelfer et al., 2008, pp. 6-7).

It would be misleading, however, to suggest that homeless people become completely disengaged from their life before an episode of homelessness. As well as maintaining the fundamental aspects of their personality, many homeless people are actively engaged in maintaining contact with their life before homelessness (Hodgetts et al., 2008, pp. 944-945). This includes strategies to maintain self-worth such as keeping up reading and studying, meaning that free public library facilities can play an important part in one's daily routine (Hodgetts et al., 2008, p. 945). Hodgetts et al. have also discussed how use of library facilities and similar public spaces help to serve other higher-level needs associated with feeling part of society (Hodgetts et al., 2008, pp. 933-935). 


\subsection{Information services and homelessness}

In a recent study into the use of technology among homeless people, Le Dantec and Edwards highlighted a digital divide among their study's participants (Le Dantec and Edwards, 2008, p. 6) that has been more fully explored by Julie Hersberger (Hersberger, 2003). Hersberger studied homeless parents to consider whether they made use of the internet and whether a lack of access resulted in them being information poor. She found that, generally, the main source of requisite information was other people, either in a formal or informal capacity, and that the internet was not considered a useful source of information (Hersberger, 2003, p. 243). This situation was not common across all participants - some did make significant use of the internet (Hersberger, 2003, p. 243) - but, considering its ubiquity in wider society, non-usage of the internet on the grounds that necessary information can be gained elsewhere could prove to be socially isolating. However, the point of Hersberger's study was that for immediate information needs the participants felt well-served, despite not using the internet; none answered that they were information poor (Hersberger, 2003, pp. 243, 246-248) and, if anything, they felt that they were suffering from information overload because information was often supplied by service providers whether they sought it or not (Hersberger, 2003, p. 247).

The role that information professionals, and particularly public libraries, can play in meeting the information needs of homeless people has also been acknowledged elsewhere. For example, Outside Story is a project in London which aims to welcome homeless people into public libraries and provide information that is "user-led" (Heffernan, 2009). However, this may be the exception rather than the rule as a recent study into Welsh public libraries found that many homeless people do not use libraries because registration requirements are prohibitive and they do not feel welcome (Harris and Simon, 2009, p. 26). Furthermore, there are also those who feel that efforts to make public libraries more accessible to homeless people are misguided and prevent "bona fide library patrons from exercising their rights." (Cronin, 2002, p. 46). However, Hersberger counters such arguments by drawing parallels with 'acceptable' groups such as toddlers "who can be smelly and loud” (Hersberger, 2005, p. 200). She also highlights the fact that the homeless are not a homogenous group and that "Categorizing an entire class of people as "problem patrons" is outright 
discrimination." (Hersberger, 2005, p. 200). Moreover, the success of a mobile library operated by The Quaker Homeless Action charity in central London illustrates that there is an extant demand for library resources among the homeless population (Oltermann, 2007).

To date, however, there has been very little consideration of the role that access to information or lack thereof plays in identity formation and social interaction among the homeless. The library and information science literature tends to focus on information required to meet basic physiological needs, how homeless people gain access to this information, and what the best ways are to deliver this information.

Although this focus is understandable when considering such a physically vulnerable group of people, there is a danger that other needs will be neglected. Given that their immediate social networks are restrictive and potentially isolate homeless people from wider society, focusing on an individual's needs simply as a 'homeless person' may be problematic, serving to perpetuate a circular logic of isolation and alienation. There is therefore a need to examine the extent to which homeless people are excluded from the informational mainstream and how this affects identity formation and social interaction among the homeless. As well as going some way towards introducing cognisance of the 'humanistic coefficient' (Snow and Anderson, 1987, p. 1365 ) into the library and information science literature about homelessness, this will also have important implications for public libraries' social inclusion efforts and the arguments for pursuing such efforts. Both of these aims are supported by calls for further research in the literature (Hersberger, 2003, p.236; Hersberger, 2005, p. 201).

\subsection{Research questions}

In order to address the research problem outlined above, the following questions were pursued:

1. To what extent are homeless people excluded from mainstream sources of information such as newspapers, radio, television, books, and the internet?

2. To what extent do informal sources provide access to the informational mainstream? 
3. What are homeless people's perceptions of the mass media?

4. What takes the place of mainstream information for identity formation and social interaction in cases where people are excluded from the informational mainstream?

\section{Methodology}

\subsection{Nature of research}

Since the higher-level needs of homeless people have received very little direct attention in existing academic literature, this study was necessarily exploratory in nature. Although this may seem to limit the research in some ways, it coheres with a guiding precept of our research that potential judgements and preconceptions of a marginalised group be minimised. As Hodgetts et al. have written concerning media portrayals of the homeless: "Homeless people are often displaced from their own stories, being talked about rather than talked to." (Hodgetts et al., 2008, p. 937). The abundance of assumptions that are made about homelessness and homeless people accentuated our feeling that participants own accounts should inform the research findings as far as possible. This is consistent with both Grounded Theory and Sensemaking approaches to research (Denscombe, 2003, p. 114; Dervin, 1992). There are of course limits to the degree to which this is possible: research often involves contrived situations which are not part of the participant's regular behaviour; arguably, meaning is generated by both parties in any exchange (Järvinen, 2003, p. 217); and the analysis of data by the researcher necessarily impacts upon its presentation and subsequent meaning (Denscombe, 2003, pp. 268-269). However, despite these limitations, we felt it important to explore participants' own narratives as the basis for investigating the research questions.

\subsection{Research methods}

Individual interviews were chosen as the primary method of data-gathering. This allowed for individual explanations, was seen as particularly appropriate if one accepts Snow and Anderson's assertion that talking plays a significant part in identity construction among homeless people (Snow and Anderson, 1987, p. 1348), and other researchers have described how homeless participants often had a preference for face- 
to-face contact so that they knew they had the person's full attention (Hersberger, 2003, p. 243; Le Dantec and Edwards, 2008, p. 8).

Semi-structured interviews allowed for flexibility of dialogue but maintained a focus on our four overarching research questions. Semi-structured interviews also facilitated effective ordering of questions so that potentially sensitive material was addressed near the end of the interview. Questions were designed to be open-ended and non-prejudicial, guided by the idea that the best way to learn someone's internal frame of reference is to allow them freedom to tell their own story (Sumerlin, 1996, pp. 888-889). The script for the interviews and a demographic questionnaire were developed using an iterative approach, including practice interviews and advice from a former social worker who had worked with homeless people for a total of 11 years and, on a separate occasion, two members of the Homeless Person's Team at Glasgow City Council, who between them have eight and a half years experience working with homeless people. ${ }^{2}$

\subsection{Sample size and demographics}

The research was conducted in collaboration with a local service agency called Glasgow City Mission which works with homeless and vulnerable adults and children. A member of the Mission staff and the Mission's project manager advised on the interview script, demographic questionnaire, information sheet, the projected verbal summary of the information sheet, and the consent form.

The first author attended the Mission on three afternoons when day clubs and activities were running, and on three evenings when food is served, between the 7 th of July 2010 and the 18th of July 2010. The interviewer was introduced to potential participants by agency staff and was then left to explain the research and what participation involved. The Mission also offered suitable, often private, places to conduct the interviews. The interviews were all audio recorded using a digital recorder and therefore required relatively quiet areas. In the event, 18 participants

\footnotetext{
${ }^{2}$ It should be stressed that all three of these people were giving advice in a completely informal capacity and that any errors of judgement belong solely with the authors.
} 
who were currently or formerly homeless were interviewed over these six sessions. This number is comparable to similar studies covered in the literature review. ${ }^{3}$

The original intention, following Hersberger (Hersberger, 2003, p. 236) and Järvinen (Järvinen, 2003, p. 216, 229), had been for interviews to last between 45 minutes and 1 hour. However, following suggestions from service agency staff that it may be difficult to maintain interest from participants over the course of a 1 hour interview, this expectation had been lowered to roughly half an hour - in line with Sumerlin (Sumerlin, 1996, p. 886) - and the interview script was developed accordingly. As it turned out, interviews ranged from about 15 minutes to about 35 minutes, totalling just over 7 hours. All participants were male because men and women often have very different experiences of homelessness (Sumerlin and Bundrick, 1997, pp. 13081310), and they were all of UK origin and Caucasian. Although questions about ethnic origin or birthplace were not asked directly, from the accents of participants and stories that they related, it appeared that most of the participants were from Glasgow, with the remainder originally from elsewhere in the UK.

At least 7 participants were either currently or formerly homeless in the long-term, according to both Ralph Anderson's (Anderson, 1996, p. 375) and David Snow and Leon Anderson's definitions (Snow and Anderson, 1987, p. 1346) of 6 or more years and over 4 years respectively. It was occasionally difficult to discern histories of homelessness, but the 6 participants who had been or were currently homeless in the short-term - having been homeless once or twice for a total of less than 6 months will be identified as such in the reporting of findings and, furthermore, still had interesting insights to relate. The remaining 6 participants had been homeless for long enough and frequently enough for this to have impacted significantly on the experiences and behaviours under consideration. Information on histories of homelessness also informed findings and will be given as background to quotations or paraphrases.

\footnotetext{
${ }^{3}$ This includes the following figures: 12 participants (Hodgetts et al., 2007, p. 712); 13 participants (Le Dantec and Edwards, 2008, p. 1); 20 participants (Hersberger, 2003, p. 236); 25 participants (Järvinen, 2003, p. 216, 229). Other studies such as Conley (1996, p. 30) and Roberson and Nardi (2010, p. 2) had significantly larger numbers of participants, 42 and 39 respectively, but these took place over a greater time period.
} 
Following the recommendation of staff at Glasgow City Mission, no economic incentive was offered to participants. As well as removing ethical issues regarding coercion, this meant that interviews could be conducted on a more informal basis, talking to participants if they were available rather than having to set up an interview schedule that some may have struggled to keep. It also meant that interviews could be terminated easily, without uncertainties over payment, if participants started to feel uncomfortable.

\subsection{Data analysis}

Preliminary notes were taken soon after each interview session to record contextual information - such as the interviewee's demeanour - that would not be picked up by an audio recording, as well as to briefly summarise the interview. These notes also served as a useful reminder of each interview that allowed a provisional plan of findings - mapped to the research questions - to be drawn up from memory and in conjunction with the notes.

A template was developed for analysing the interview notes, roughly corresponding to the interview script. Interviews were then analysed qualitatively, in line with the research questions and the provisional plan, with significant sections of the interviews being transcribed. The notes and plan were cross-referenced with each other and the original audio recording to allow iterative and participant-led development of the write-up of findings. In order to allow this iterative and fluid approach, no formal coding scheme was employed; rather, the provisional plan developed with increasing granularity under the headings of the guiding research questions. This led to some imbalances - such as greater space being dedicated to the first research question in the Findings section - but it meant that the findings were more reflective of what participants actually said and of where their own emphases lay. In other words, we tried to make the data shape the write-up, rather than imposing a pre-existing structure on the data. 
Despite this approach, there are naturally limitations to the degree of objectivity possible in the presentation of findings. As Madden argues, it is important to acknowledge the limits of objectivity and avoid claiming to be able to understand and represent "the researched" more than is actually possible, since this serves to disempower rather than empower participants (Madden, 2003, pp. 300-301). In order to mitigate distortion of findings, this paper will incorporate extended quotations ${ }^{4}$ to allow the participants to tell their own stories.

\subsection{Data validation}

As part of the process of data validation, repeat interviews are attractive (Denscombe, 2003, p. 186) but these were not deemed practical, particularly given the potential for low response rates among the population with whom we were working (Le Dantec and Edwards, 2008, p. 4, 9). Instead, findings were checked more widely with other sources, reflecting the idea of triangulation to corroborate findings (Denscombe, 2003, pp. 131-134). Firstly, the interviewer was careful to try to understand what participants meant, asking repeat questions where necessary and approaching issues from different angles to gain a fuller picture. Secondly, findings and conclusions have been explicitly and implicitly informed by the literature review that was undertaken to initiate this research. This serves to corroborate findings by aligning trends in the interview data with trends that have been observed elsewhere by others. Finally, following the process of data analysis, a summary of findings was drawn up and checked with the project manager of a homeless service agency who has 16 years experience of working with homeless people. This serves to widen the sample by proxy as well as providing an external but well informed perspective on various facets of homeless people's situation.

\subsection{Limitations}

This study was reliant on volunteers and the demographics were subsequently not always consistent in terms of histories of homelessness and reasons for homelessness.

\footnotetext{
${ }^{4}$ Quotations are presented in Standard English rather than their original vernacular form. It was felt that using vernacular language would be an unnecessarily parochial approach, aiming for misplaced authenticity at the expense of wider comprehension. Perhaps more importantly, it may also produce a patronising picture of frequently articulate people who, if communicating the same information in writing, may similarly use Standard English.
} 
However, although this is a limitation of the study, for the reasons discussed above it should not obscure the findings, and in some cases may provide useful contrast and different perspectives. Probably more significant was that our study was limited to Glasgow and therefore does not account for rural homelessness. Furthermore, according to various people who were interviewed, both homeless people and service agency staff, the provision for homeless people in Glasgow is better than in many other areas. This may mean that positive aspects of the findings may not be generally applicable since they are reliant on service provision specific to Glasgow.

Another limitation is that the interviewer was perhaps directed by staff towards people who were least likely to cause problems and would be most able to answer questions. This problem is also compounded due to the suspicion with which the research, and particularly the recording of interviews, was held by some potential participants. The findings may therefore be skewed towards more confident and resourceful people, to the inadvertent exclusion of those who are more marginalised. However, several of the participants had concerns over the anonymity of the research, sometimes asking for repeated reassurance in this regard, while others related very difficult life experiences that had obviously affected them significantly. In other words, although the study may have an unintentional bias towards more confident people, this should not be seen as all encompassing or exclusively the case.

\section{Findings}

In this section we present our findings with respect to the four main research questions. Participants will remain anonymous and be identified numerically rather than by name, e.g. 'Participant 1 '.

\subsection{To what extent are homeless people excluded from mainstream sources of information such as newspapers, radio, television, books, and the internet?}

As the interviews got underway it quickly became clear that many homeless people are generally neither circumstantially nor emotionally excluded from mainstream sources of information. Indicative of this was that a number of participants $(1,3,6$, 10,13 and 15) mentioned a recent high-profile news story. Several participants (5, 
11, 12, 14, 15 and 16), particularly Participant 5, explained that, although their activities and interests were curtailed by homelessness, this was due to economic and circumstantial constraints rather than through lack of access to mainstream information sources. Participants related that they could get access to these sources in a number of ways, even if they were often restricted by location or the time of day.

Television was a major source of information for many of the participants. This was accessible in some service agencies, through communal television rooms in some hostels, or at friends' houses, although the latter seemed to be limited to people who were homeless in the short-term. Furthermore, televisions were not seen as prohibitively expensive for all participants. For instance, Participant 7, who was no longer homeless but had stayed in various hostels for 6 years previously, said that he always made sure that he had his own television when staying in hostels, often using Teletext to keep up with the news.

However, several participants, such as Participant 7, expressed frustration with communal television due to people talking over programmes, people wanting to watch different things, and not necessarily wanting to associate with other people using the communal facilities. As Participant 14, who had been homeless briefly on two occasions in the past year, related:

...they had a TV room [in the hostel] so I'd go along to there now and again but it was full of a bunch of dafties [idiots] half the time...like people that are alcoholics and all that and that's just people I don't want to be around... [But] you can come here [to Glasgow City Mission] at night time and you can get something to eat and it helps you a lot because if it wasn't for these places you'd have nowhere to go.

The desire to be elsewhere during the day if staying in hostels, or the need for somewhere dry, safe and warm if sleeping rough, meant that many of the participants made extensive use of service agencies, public libraries and bookshops when homeless. As well as providing somewhere to be and something to do, these places 
also gave people access to various sources of information such as books, newspapers and internet facilities, with service agencies often running computer classes and literacy classes. However, internet access is restricted to 2 hours a day in Glasgow public libraries, and computer classes in service agencies only run at certain times, on certain days. Nonetheless, when asked about difficulties they faced in accessing these sources of information, most participants stated that they did not have a problem. Several participants (3, 4 and 9) also made specific reference to staff at service agencies who were valued as a non-judgmental and very helpful way to find out about things.

One participant (15), who was sleeping rough and might be considered to face particular difficulties regarding information access, provided a fairly typical response that, in terms of accessing information, "there's always ways and means...if you're determined to find out something you can do it."

Although it is believed to be widespread (Warnes et al., 2003, p. 35) and is often identified as potentially causing and exacerbating difficulties associated with homelessness (e.g. Simmons, ND), the true extent of illiteracy among homeless people in the UK is unknown due to a lack of hard data (Warnes et al., 2003, p. 35). Illiteracy may also be underrepresented in this study because people who have literacy issues are more likely to be lacking in confidence and wary of signing up to things that they cannot fully comprehend on their own terms. However, despite this potential under-representation, there were still some telling comments in this regard. Although not illiterate, Participant 6 expressed frustration that his dyslexia made reading very difficult for him, despite his desire to read books;

It's not that [I don't have time or lack interest], it's because I'm dyslexic it's really hard for me to concentrate. See when I'm reading a book - it's hard to explain - it's like the words are jumping, and I can't focus. It's really hard; I need to take my time with it... [It's] frustrating... Oh, I'd like to read a book though. 
As well as functional literacy issues, ICT illiteracy can also be a barrier to information access. For two of the older participants (8 and 12), computer literacy posed a problem. When asked whether he felt that he was missing out due to lack of access to the internet, Participant 8 said wistfully that he did, but that he needed someone to teach him how to use computers. For Participant 12, who had been homeless for 5 years, computer literacy was more a matter of practical necessity:

[The internet is]...something I've been realising I have to, at one point, get to grips with; recently more so [since] the price of using a public telephone box has gone up to 60p [and] I really can't afford that. So I'm going to have to learn how to text and start doing basic things. Should I go back to work I need to know how to do e-mails and banking and just basic internet stuff.

However, he did not feel that homelessness in itself had stopped him from pursuing this:

No, I could go to college and do it. There are facilities available to people should you wish to go and do it. Just a chaotic lifestyle has stopped me from doing these things.

This highlights discrepancies in information access between those, like Participant 12 , who are aware of the opportunities and facilities available and those who are unaware of these for whatever reason - perhaps like Participant 8 , who had only very recently become homeless. Furthermore, it also indicates the potential influence that one's lifestyle or priorities can have on information access.

As well as creating different priorities, one's lifestyle and circumstances can also affect information access due to potential exclusion from public spaces. For example, when using library facilities, adherence to middle-class expectations of behaviour is important to avoid appearing as a threat and being ejected from the library (Hodgetts et al., 2008, pp. 941-942). Indeed, as well as facing practical difficulties in obtaining 
library cards with no address, Participant 10 also described how visiting libraries was psychologically difficult when he was homeless:

There was a certain amount of shame to the way I was leading my life as well, and I felt like walking in there, I didn't really feel part of...I wasn't just your normal Joe Bloggs walking in to a library to sit down and read a book; so quite uncomfortable doing that stuff then. Now I've not got a problem with it. You know back then, it could be quite uncomfortable. But obviously now things being a lot better and stuff, and two and a half years, three years, clean now I feel a lot more confident to do the things that I used to do before.

[emphasis in original]

Furthermore, when asked if he felt he had been made to feel uncomfortable in certain situations, Participant 15 answered in the affirmative:

Oh, definitely; not so much [in] libraries but in shops and cafes and that, definitely...you feel as though [people are] looking down their nose at you just because you're walking about with your big rucksack and maybe your sleeping bag and they automatically think [that] because you're homeless you're up to something, you're going to steal from them or you're up to something bad.

Participant 12 also made reference to the judgements people were likely to make about those who are homeless. Moreover, numerous participants (9, 14 and 17) were quick to point out that they did not take drugs or drink to excess, pre-empting possible judgements on the part of the researcher. This is consistent with Järvinen's findings that people often stressed that their homelessness was caused by issues other than alcohol and drugs (Järvinen, 2003, pp. 220-223). However, although it could be socially isolating, several participants $(4,17$ and 18) used their awareness of possible prejudice and put some effort into their appearance to mitigate its effects. 
As Hodgetts et al. described in the context of library use, maintaining contact with one's life prior to becoming homeless is often vital for self-esteem and maintaining one's sense of self (Hodgetts et al., 2008, pp. 944-945), which is reflected in the comments of several participants. In response to whether he felt that the mass media were relevant to him, Participant 5, who had been homeless intermittently for the past 8 years, responded:

Oh, yeah. If I didn't have them I'd probably go mad because, at the end of the day, I've been used to them all my life. It's part of my life basically using those kind of things [TV, radio, newspapers, etc.].

Similarly, when asked if he felt like he was missing out when he did not have access to various mass media, Participant 15 replied:

It's a weird one because you take it for granted, but then when you're on the streets you've not got access to the TV and it's definitely a void, it's not there. Yeah, you miss it; even just the silly things, like watching Eastenders or stuff like that.

Overall, the participants in this study did not seem to have much difficulty accessing mainstream information sources. They were aware of various places where one could get cheap or free access to information sources and made extensive use of these. Similarly, although many were very conscious of possible prejudice based on their circumstances, they also often had strategies for dealing with this. However, the sample in this study may be under-representative of people lacking in confidence, including those with literacy issues, who may experience greater difficulties in a number of respects. Furthermore, for people with addictions, information access is often not a priority, meaning that, despite the availability of mainstream information, individuals in this position will potentially experience increasing isolation from wider society. 


\subsection{To what extent do informal sources provide access to the informational mainstream?}

In this paper, 'informal sources' essentially means other people and information which is shared conversationally, as distinct from published material or broadcasting. Given that, contrary to initial expectations, there was generally not exclusion from more official sources, informal sources did not really need to provide access to the informational mainstream. However, mainstream information was certainly an important subject of conversation. This section will focus on various facets of the latter and consider how homelessness may affect socialising, and how the internet may affect the social world of some homeless people.

Meeting new people was often mentioned as one of the few positive aspects of becoming homeless. Participant 7 said that when he had been living in hostels, there were always people around so socialising was very easy. Others (Participants 13, 16 and 17) also mentioned that as a result of being homeless they had met new people, and spoke of having quite varied social circles. Talking to other people was mentioned as a good way to get information (Participant 6), combat loneliness (Participant 2), and as a positive way to pass the time that was integral to one's personality (Participants 2, 4, 6, 8 and 12).

However, lack of private space to relax, away from other people, was also mentioned as a negative aspect of being homeless by Participant 12. Furthermore, homelessness can be socially isolating in a number of ways. In spite of Participant 7's experiences, a number of participants alluded to difficulties and dangers when staying in homeless hostels. For many people, being in this new, socially problematic situation is likely to be particularly difficult since, concurrently, contact with existing friends may become strained. As Participant 13, who was only homeless for a very short period of 2 to 4 weeks, recounted:

Well I found [that] when I was in a hostel I didn't see as much of my friends as I did beforehand, and the people that were in the hostel I just didn't really want to associate with - not saying that I was better than them or anything, but I just didn't want to go down that road of maybe 
getting to know them and whatever they were involved in, me getting kind of dragged into it. Although my interests were still in my music and stuff like that ... a lot of the friends I had ... kind of drifted away...

Other participants also often had similar stories to relate; from the absence of previous social contact at work (Participant 11), to exclusion from previous social situations either through lack of money or curfew restrictions in hostels (Participants 12 and 17). On the positive side, several of the same participants and others made reference to service agency staff filling this void to some degree, and also being particularly helpful in discussing problems in a non-judgemental and sympathetic way.

Although it was not universal, a significant proportion of respondents felt that it was important to keep up with current events; Participants 1, 5, 6, 7, 8, 9, 10 and 15 all made a considerable effort to get regular access to the news through various means. This often served conversational functions and perhaps also, as in the case of TV, provided a connection to the outside world and to one's life prior to homelessness. However, homelessness may also influence and restrict people's information access. Numerous participants $(5,6,8,10,15$ and 16) seemed to get most of their news from a limited number of inexpensive or free newspapers.

In terms of maintaining one's social connections in spite of a homeless episode, the internet has significant potential. A number of participants $(2,4,6,7,10,11,14,15$ and 16) mentioned using the internet for social functions. The reasons given for this in some, but certainly not all, of these responses reflect the findings in Le Dantec and Edwards study that mobile telephones are valued by homeless people because they allow them to keep in touch with people but also stay in control of the interaction and keep the person at arm's length (Le Dantec and Edwards, 2008, pp. 4-6).

\subsection{What are homeless people's perceptions of the mass media?}

An important question was whether perceptions of mass media would be qualitatively altered by homelessness. On the one hand, although there were mixed responses to 
questions about perceptions of advertising, with some participants expressing an interest and others expressing indifference, these statements seemed to be attributable more to personal disposition than any sense of alienation from advertising due to homelessness. On the other hand, though, there were notable results in terms of mass media perceptions among some participants that may be attributable to homelessness and not consonant with the population at large.

Firstly, there seemed to be a widespread distrust of news media and particularly newspapers, despite the fact that these were a major source of information for many participants. Several participants $(10,12,17$ and 18) expressed an interest in how events are portrayed in the news, taking a very critical, detached perspective that illustrated a high degree of awareness of media manipulation and bias. Although such attitudes are obviously not limited to the homeless population, it is consistent with Sumerlin's discussion of heightened self-awareness among the homeless (Sumerlin, 1996, p. 887), and an impression communicated by various participants, that the experience of homelessness has given them an additional perspective on life.

Secondly, some participants' (2,12 and 14) experience of homelessness, or with contributory factors leading to homelessness, gave them a particular aversion to some aspects of the mass media. Participant 12 related an account of how fundamental changes in his life had altered his use of the mass media. He said that a nervous breakdown had eventually led to him becoming homeless. When asked about whether he watched TV now he said:

No, very rarely; in my parents' house I watch it a tiny little bit. But I've not had a television since the late '90s, initially out of choice and then because of homelessness. Initially, when I had my breakdown I realised I was addicted to television; I was watching it and I couldn't not watch it so I considered that I was hooked on television... I wanted to write and paint and I couldn't write or paint because I was sitting looking at a television set. So I put it out, I think 1998 I put it out - not had one since. 
Similarly, although he did make use of it, Participant 14, who lost his job, alienated himself from various friends, and became homeless due to a gambling addiction, seemed wary of the addictive nature of the internet. Therefore, although homelessness does not necessarily influence how people perceive the mass media and other information sources, it seems that in some cases traumatic life events can produce a wariness or aversion to certain kinds of information and certain activities. This may be worth bearing in mind when providing services as seemingly erratic or irrational responses may be attributable to past difficulties that require sensitivity.

\subsection{What takes the place of mainstream information for identity formation and social interaction in cases where people are excluded from the informational mainstream?}

At least among the participants in this study, access to the informational mainstream was not particularly curtailed by homelessness. Indeed, for many of the participants, the information sources considered in this paper were important ways to fill the time, and they also concurrently played a vital role in providing a means of escapism. As discussed previously, television serves a number of different functions from providing useful information (15) or filling time (5, 6, 7 and 9), to providing a sense of escapism or a connection to life before homelessness (5 and 15). A number of participants (2, $3,4,10$ and 14) mentioned that films were one the main things - and for some the only thing - that they watched on television, with Participant 14 instructively saying that soaps and films sometimes helped him "forget about things". Books also played a significant role in terms of escapism. Several participants (3, 5 and 9) predominantly read fiction and this seemed to fulfil a similar role to films.

We also saw evidence of use of information as a therapeutic device (Ouzts, 1991). For example, although the news was something he wanted to avoid, Participant 2 found reading therapeutic and useful to guide his work helping others:

I read books about true stories, [about things like] children who have been abused....and how their life changes around when they get all the help they need - similarities to what happens to other people in life that 
have been neglected or abused or whatever. ... When I was a child I was abused, physically quite a bit, and once sexually... and that's why I like to read things about child abuse - how they pulled through, the help they got - because it's therapy; it helps me to know [that] the work is working slowly, but not for as many as we'd like it to.

Similarly, for Participant 12, reading has been a significant part of recuperating from a nervous breakdown:

I've been introduced to it [psychology] to help facilitate my own recovery, so I've been reading it these last few years just to help...I had therapy beforehand, it didn't work. ...I've been reading quite a lot in these last, I'd say, five years. I've switched subjects and started reading social sciences a little bit, which I'd never read before couldn't have read, wouldn't have understood - until I put myself into the picture and my family into the framework of the text.

As well as escapism and learning about oneself, reading and learning also seemed to be an important way to boost self-esteem for many participants. This is significant because numerous statements from participants also indicated that they were lacking in confidence, which coheres with the discussion in the literature review regarding the impact of homelessness on self-esteem. However, it is worth noting that several participants $(2,10,12,13,14,15,16,17$ and 18) also made statements suggesting that they had learned a lot through experiencing homelessness. Participant 6 stated this most clearly and explicitly in the context of a wider discussion about service provision and the necessity of having firsthand experience of being homeless:

I'm a stronger person because of it [experiencing homelessness]. [I] see things in a totally different way now. It's helped me grow up and I think I needed that. 


\section{Discussion}

From our interviews it appears that homelessness does not necessarily affect access to the informational mainstream. Therefore, although homelessness can be socially isolating in other ways, it does not appear that exclusion from mainstream sources of information will generally compound this experience. Again we acknowledge the likely emphasis on more confident, resourceful individuals, who also happen to live in a city with relatively good provision for the homeless. Further research in a different locale and among less confident individuals would therefore be necessary to corroborate findings in this regard. However, what we see arising in discussions with the participants in this study is the ability to find ways to cope with restricted access to mainstream information sources. Many participants stressed the importance of maintaining contact with mainstream news events and were able to do this largely through free or inexpensive newspapers and access to television or the internet. Although social contacts and informal sources may change if a person enters into a homeless situation, most participants stated that their main interests remained unchanged by their circumstances; new practical information needs often arose and a new sense of perspective may have emerged, but this generally did not represent a fundamental shift in identity formation or the kind of information that was of interest.

Similarly, it became apparent during interviews that homelessness itself is definitely not the defining characteristic of a person in that situation. This is not to deny that homelessness represents a set of circumstances that is alien to anyone who has never experienced it, as recognised by several of this study's participants. However, it is easy to subconsciously assume a degree of 'otherness' which does not exist. Specifically, and in line with what has already been said, the participants in this study unquestionably sought to service higher-level as well as physiological needs, which coheres with the discussion undertaken in section 2.

A number of the findings in this regard are pertinent to library and information science. Firstly, various information sources facilitated escapism and relaxation for a number of participants. In the context of social isolation, unpleasant living conditions and traumatic life events, both past and present, the ability to switch off and distract oneself can be a vital corollary of serving more basic needs for food, clothing and 
shelter. However, this can also be very problematic with meagre financial resources; as Participant 12 put it, "It's pretty hard to pass time when you're homeless and skint." The relative inexpensiveness of radios, newspapers and books makes these useful sources of escapism that are often accessible even in a difficult economic position. Moreover, even for people whose financial resources will not stretch that far, internet facilities in service agencies and public libraries, and the ability to borrow newspapers and books without charge, can fulfil this role. However, this is obviously contingent on people having functional and/or ICT literacy.

Secondly, for a number of reasons, people who become homeless often lack confidence. As well as facilitating escapism, education in the use of, and access to, information sources such as the internet and books may partially address these issues. The internet can obviously open up access to huge amounts of information as well as fulfil social functions, such as allowing people to keep in touch with others on their own terms. Books can widen a potentially curtailed information environment and give people more confidence about themselves, challenging possible prejudice and perhaps addressing more deep-seated self-esteem issues.

With regard to both these points - facilitating escapism and addressing self-esteem issues - public libraries can and do play an important role. For many of the participants in this study, as described in the Findings section, public libraries were an important place to spend the day, get access to the internet, and read books and newspapers. As mentioned previously, broad generalisations about 'homeless people' are extremely problematic and this research supports Hersberger's dismissal of prejudicial public library policies based on arbitrary and inconsistent criteria (Hersberger, 2005).

In terms of assisting people who are homeless, greater collaboration with service agencies may be desirable to extend adult literacy and ICT training programmes. As well as providing important employability skills, this will open up greater opportunities for people to make use of library stock and ICT facilities to service higher-level needs such as escapism and boosting self-confidence. 
In summary, our research concentrated on high-level needs of people who find themselves homeless. We have indicated the importance of such information for socialisation, self-esteem and, in some cases, coping with difficult life experiences. In many ways these uses of information are similar to those in settled housing. What is different is the context in which such needs arise and the context in which they need to be managed. By focussing particularly on higher-level needs we hope to reassert the importance of understanding these important needs in homeless populations.

\section{Acknowledgements}

We are very grateful to the staff and clients of the Glasgow City Mission who generously shared their time and experiences with us. We are also grateful to the individuals mentioned in the Methodology who assisted in the preparation for the interviews. A fuller account of this study can be found in Muggleton (2010).

\section{Bibliography}

Anderson, R. (1996), "Homeless Violence and the Informal Rules of Street Life", Journal of Social Distress and the Homeless, Vol. 5 No. 4, pp. 369-380.

BARB (Broadcasters' Audience Research Board), (2010), Television Ownership in Private Domestic Households 1956-2010 (Millions), Broadcasters' Audience Research Board Limited, London. Available: http://www.barb.co.uk/facts/tvOwnershipPrivate (accessed 16 ${ }^{\text {th }}$ June 2010).

Barry, P. J., Ensign, J. and Lippek, S. H. (2002), "Embracing Street Culture: Fitting Health Care into the Lives of Street Youth", Journal of Transcultural Nursing, Vol. 13 No. 2, pp. 145-152.

BML (2010), Sizing the UK Book Market, BML, London. Available: http://www.bookmarketing.co.uk/index.cfm/asset_id,885/index.html $\quad$ (accessed $16^{\text {th }}$ June 2010). 
Conley, D. C. (1996), "Getting It Together: Social and Institutional Obstacle to Getting off the Streets", Sociological Forum, Vol. 11 No. 1, pp. 25-40.

Cronin, B. (2002), "What a library is not”, Library Journal, Vol. 127 No. 19, p. 46.

Cronley, C., Strand, E. B., Patterson, D. A. and Gwaltney, S. (2009), "Homeless people who are animal caretakers: a comparative study", Psychological Reports, Vol. 105, pp. 481-499.

Daly, M. and Silver, H. (2008), "Social exclusion and social capital: A comparison and critique", Theory and Society, Vol. 37 No. 6, pp. 537-566.

Denscombe, M. (2003), The Good Research Guide for small-scale social research projects, Open University Press, Maidenhead.

Dervin, B. (1992), "From the mind's eye of the user: the sense-making qualitativequantitative methodology”, in Glazier, J. D. and Powell, R. R. (eds.), Qualitative Research in Information Management, Libraries Unlimited, Englewood, CO, USA, pp. 61-84.

Feather, J. (2008), The Information Society: A study of continuity and change, Fifth edition, Facet Publishing, London.

Harris, N. and Simon, A. (2009), "Still barriers to overcome", Public Library Journal, Vol. 24 No. 4, pp. 25-27.

Heffernan, F. (2009), “Outside Story: welcoming the homeless", Public Library Journal, Vol. 24, No. 3, pp. 6-7.

Hersberger, J. (2005), "The Homeless and Information Needs and Services", Reference and User Services Quarterly, Vol. 44 No. 3, pp. 199-202.

Hersberger, J. (2003), “Are the economically poor information poor? Does the digital divide affect the homeless and access to information?" CAIS/ACSI 2003, pp. 236-249. 
Hodgetts, D., Stolte, O., Chamberlain, K., Radley, A., Nikora, L., Nabalarua, E. and Groot, S. (2008), “A trip to the library: homelessness and social inclusion”, Social \& Cultural Geography, Vol. 9 No. 8, pp. 933-953.

Hodgetts, D., Radley, A., Chamberlain, K. and Hodgetts, A. (2007), "Health Inequalities and Homelessness: Considering Material, Spatial and Relational Dimensions", Journal of Health Psychology, Vol. 12 No. 5, pp. 709-725.

Järvinen, M. (2003), "Negotiating Strangerhood: Interviews with Homeless Immigrants in Copenhagen”, Acta Sociologica, Vol. 46 No. 3, pp. 215-230.

LaGory, M. Fitzpatrick, K. and Ritchey, F. (2001), "Life Chances and Choices: Assessing Quality of Life among the Homeless", The Sociological Quarterly, Vol. 42 No. 4, pp. 633-651.

Le Dantec, C. A., and Edwards, W. K. (2008), "Designs on Dignity: Perceptions of Technology Among the Homeless", in: CHI '08: Proceeding of the twenty-sixth annual SIGCHI conference on Human factors in computing systems, ACM, Florence, Italy, pp. 627-636.

Madden, M. (2003), "Braving Homelessness on the Ethnographic Street with Irene Glasser and Rae Bridgman”, Critique of Anthropology, Vol. 23 No. 3, pp. 289-304.

Muggleton, T. (2010), “The Effect of Homelessness on Information Access, Identity Formation and Social Interaction”, MSc thesis, University of Strathclyde.

Office for National Statistics (ONS) (2010), Use of the Internet, Office for National Statistics, London.

Office of the Law Revision Counsel. (2009), 42 USC CHAPTER 119 - HOMELESS ASSISTANCE (01/05/2009), Office of the Law Revision Counsel of the U.S. House of Representatives, Washington, DC. 
Oltermann, P. (2007), "Hannibal Lecter saved my life", The Guardian. Available: http://www.guardian.co.uk/books/2007/mar/31/featuresreviews.guardianreview1 (accessed $2^{\text {nd }}$ August 2010).

Ouzts, D.T. (1991), “The Emergence of Bibliotherapy As a Discipline”, Reading Horizon, Vol. 31, pp. 199-206.

Penguin English Dictionary (2007), "social exclusion", The Penguin English Dictionary, Penguin, London.

RAJAR (Radio Joint Audience Research Limited) (2010), Listening Figures Quarterly Listening. Radio Joint Audience Research Ltd., London. Available: http://www.rajar.co.uk/listening/quarterly_listening.php (accessed $29^{\text {th }}$ June 2010).

Roberson, J. and Nardi, B. (2010), "Survival Needs and Social Inclusion: Technology Use Among the Homeless" in: CSCW 2010, February 6-10, 2010, ACM, Savannah, Georgia, USA.

Simmons, W. (ND), Tackling Exclusion: Literacy and Homelessness in NI. Law Centre (NI), Belfast. Available: http://lawcentreni.org/publications/frontlinemagazine/374.html (accessed $11^{\text {th }}$ August 2010).

Slesnick, N., Glassman, M., Garren, R., Toviessi, P., Bantchevska, D. and Dashora, P. (2008), "How to open and sustain a drop-in center for homeless youth", Children and Youth Services Review, Vol. 30 No. 7, pp. 727-734.

Snow, D. and Anderson, L. (1987), "Identity Work among the Homeless: The Verbal Construction and Avowal of Personal Identities", The American Journal of Sociology, Vol. 92 No. 6, pp. 1336-1371. 
Sumerlin, J. R. (1996), "What have you learned from your homeless experience? A phenomenological approach for counseling unsheltered homeless men", Psychological Reports, Vol. 79, pp. 883-890.

Sumerlin, J. R. and Bundrick, C. M. (1997), "Research on homeless men and women: existential-humanistic and clinical thinking", Psychological Reports, Vol. 80, pp. 1303-1314.

Warnes, A., Crane, M., Whitehead, N. and Fu, R. (2003), Homelessness Factfile. Crisis, London.

Available:

http://www.crisis.org.uk/data/files/publications/factfile_Full.pdf $\quad$ (accessed $11^{\text {th }}$ August 2010).

Willings Press Guide (2007), Willings Press Guide 2007; Volume 1: United Kingdom. Romeike Ltd., Chesham, Bucks.

Woelfer, J. P. and Hendry, D. G. (2009), "Stabilizing Homeless Young People with Information and Place", Journal of the American Society for Information Science and Technology, Vol. 60 No. 11, pp. 2300-2312.

Woelfer, J. P., Yeung, M. W., Erdmann, C. G. and Hendry, D. G. (2008), "Value Considerations in an Information Ecology: Printed Materials, Service Providers and Homeless Young People", Proceedings of the American Society for Information Science and Technology, Vol. 45 No. 1, pp. 1-9. 